How to cite: Fijko, R., Zeleňáková, M. (2019) Verification of the Hydrodynamic Model of the Slatvinec River in Kružlov. 2019 "Air and Water - Components of the Environment" Conference Proceedings, Cluj-Napoca, Romania, p. 91-98, DOI: 10.24193/AWC2019_09.

\title{
VERIFICATION OF THE HYDRODYNAMIC MODEL OF THE SLATVINEC RIVER IN KRUŽLOV
}

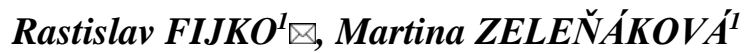

DOI: 10.24193/AWC2019_09

\begin{abstract}
In water management field, the use of computer software is essential, and it is desirable that a professional knows not only how to correctly use outputs from individual mathematical models in his work, but that he be able to manage the creation of a model itself. The calibration and the verification of the model developed directly by the designer are necessary. From the viewpoint of flood protection and prevention, it is important to know which parts of the river flood-plain may be subject to flooding. One of the outputs in flood risk assessment which is important to flood protection is flood hazard and flood risk map created based on hydrodynamic modelling. The goal of this paper is to familiarize with processes of commencing work in the program HEC-RAS, the entering of geometric data and boundary conditions necessary for initializing and presenting the results on a model of the Slatvinec stream in the village of Kružlov. The paper is focusing of verification of the created hydrodynamic model.
\end{abstract}

Keywords: 1D modelling, Kružlov, natural stream, regulated stream, GIS, validation

\section{INTRODUCTION}

Flood is a common catastrophic natural hazard, which causes severe damages to the life and area of interest (Rozalis, et al. 2010). According to Kron (2005), flood is the result of substantial precipitation or melting snow that creates an overflow situation on the river and temporarily become stagnant to the lands along the river. Flood can be occurred because of a river overflowing as well as sudden cloudburst in semi-arid regions, which leads to flash flood (Tehrany, et al. 2013). However, the flood occurrence due to the overflow of the river can easily be measured by employing proper methodologies using modern technologies (Jonkman, 2005; Tehrany, et al. 2013).

Inundation mapping is an interdisciplinary exercise that involves geomorphic and remote sensing based methods and provides insight into the hydrologic and geomorphic linkage within a flood plain (Frazier and Page, 2000). Hydraulic models of overland flow allow river discharge to be related to flood inundation extent and provide the capability to simulate flooding based on a scenario and actual discharge. Surface elevation remains one of the most important data for models, as topography

\footnotetext{
${ }^{1}$ Technical University of Kosice, Faculty of Civil Engineering, Institute of Environmental Engineering, Vysokoskolska 4, 042 00, Kosice rastislav.fijko@tuke.sk martina.zelenakova@tuke.sk
} 
is the main variable that affects the movement of the flood wave, and the prediction of inundation extent (Bakimchandra, 2006).

For the purpose of flood inundation map development, researchers use modelling approach particularly numerical model as the common tools. The performance of the models depends on the calibration process to a specific historical flood event. After that it can be used to estimate flood extents with some scenarios of event magnitudes (Domeneghetti, et al., 2013). Furthermore, they also can define scenario in several possibility and supply important information to support structural mitigation planning (Poretti and Amicis, 2011).

The research presented here consists of hydraulic modelling inevitable for flood damage assessment and effective flood protection. This article is presents a method of 1D mathematical modeling and his verification depicted on the example of the flood in the east of Slovakia in the village of Kružlov of 2008.

\section{DATA AND METHODS}

\subsection{Study area}

The village of Kružlov (Figure 1) is located in the south-western part of the Low Beskid Hills in the Slatvinec Valley in the Bardejov district. The watercourse of the Slatvinec stream was of natural character, the river banks were damaged, and the river bed was silted from erosion and also due to human activity before its regulation. The Slatvinec River, damaged by floods in 2006, 2008, 2010, was regulated in 2015. A local road runs along the left side of the stream, and on the right bank there are family houses with gardens (Zeleňáková and Zvijáková, 2017). Creating a hydrodynamic model helped with the choice of appropriate flood protection measures by ensuring cost-effectiveness.

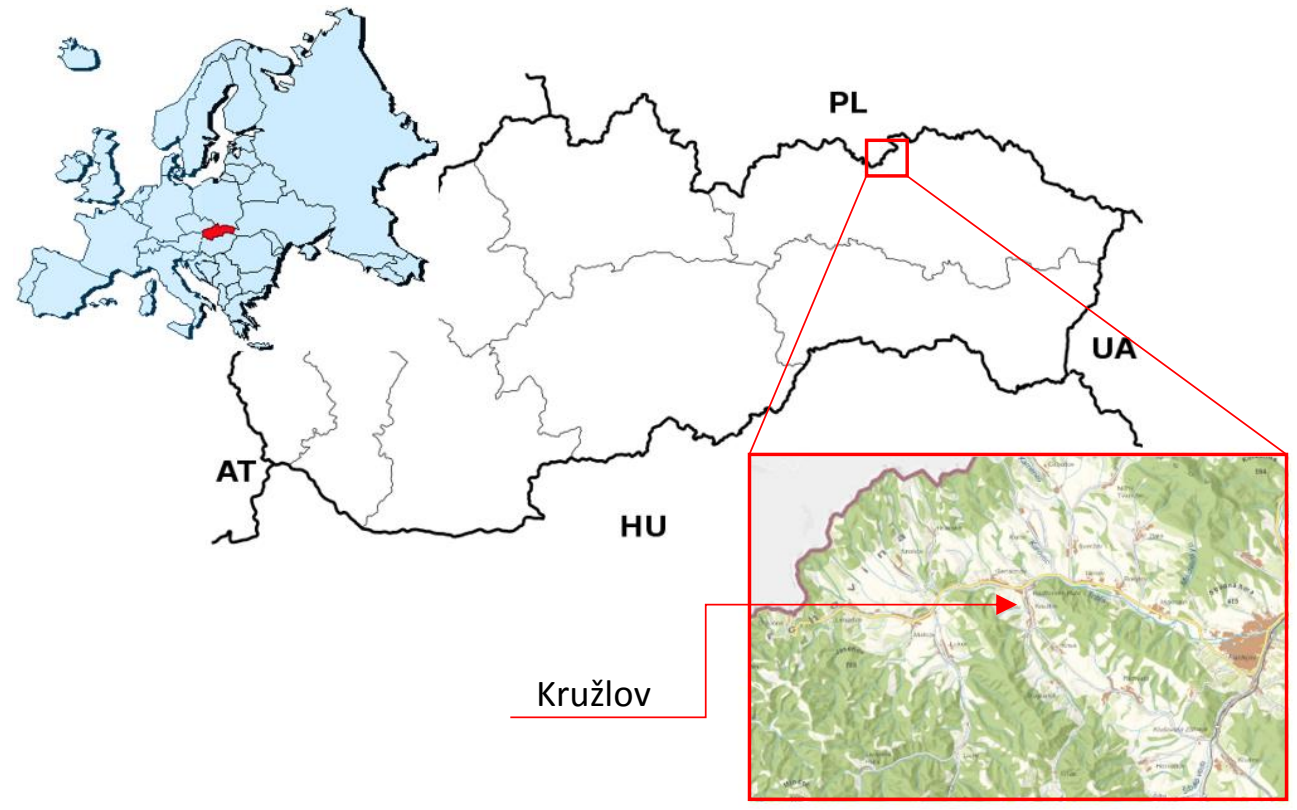

Fig. 1. Location of the Kruz̆lov village (source: Google maps) 


\subsection{D mathematical model}

Resolving a 1D mathematical model requires good analytical skills and the obligation to understand the overall required aim. Hydrodynamic models are tools that can be used for solving the continuity of flow across various temporal and spatial scales. They can be used for the simulation of flood events and flooding for engineering, planning and risk assessment studies (Nicholas and Mitchell, 2003). In this study, the freely available Hydrological Engineering Centre River Analysis System (HEC-RAS) version 5.0 hydraulic model (U.S. Army Corps of Engineers, 2016) was applied. For obtaining objective information, continuous monitoring, consisting in the collection, processing, assessment and archiving of measured data with the use of the whole spectrum of methods and special instrumental techniques is necessary (Komi, et al., 2017). From the results of the modelling it is possible to deduce the maximum height of the water level, the range of inundation, the flow of water, or the speed of the current, and do so with a change of Manning's roughness coefficient $(n)$ in each transverse profile. The calculation of such a model runs in the form of a description of the water flow in the direction of the flowing current. The placement of the transverse and valley profiles are defined in space, which in the case of $1 \mathrm{D}$ modelling is depicted as the stationing of individual profiles with the dimensions of the bottom and the banks. By combining the individual data from a graphical solution of the transverse profiles a lengthwise profile of the subject water flow is created (Fijko, 2015).

The HEC-RAS model solves the Saint Venant equations formulated for natural channels $(1,2)$ (U.S. Army Corps of Engineers, 2016):

$$
\begin{aligned}
& \frac{\partial A}{\partial t}+\frac{\partial Q}{\partial x}=q_{l} \\
& \frac{\partial Q}{\partial t}+\frac{\partial(Q 2 / A)}{\partial x}=g A \frac{\partial H}{\partial x}+g A S_{f}=0
\end{aligned}
$$

where $A$ is the cross-sectional area perpendicular to the flow $(Q)$,

$q_{l}$ is the lateral inflow due to tributary,

$g$ is the acceleration due to gravity,

$H$ is the stage or elevation of the water surface above a specified datum,

$S_{f}$ is the longitudinal boundary friction slope;

$t$ and $x$ are the temporal and longitudinal coordinates, respectively.

Hydrodynamic modelling is a useful, efficient tool for identifying flooded areas and producing estimates of spatially-distributed variables such as rapidity, depth and extent of flood inundation. One-, two- and three-dimensional hydraulic models are now widely used for this purpose. Ivanova and Ivanov (2016) presented 1-D mathematical modelling of flood wave propagation in Krasnodar in Russian Federation. Dimitriadis et al. (2016) applied 1D and 2D hydraulic models for two case studies in Greece. Fijko et al. (2016) used 1-D HEC RAS modelling for flood damage assessment in Lopuchov in Slovakia. Romanescu and Stoleriu (2018) developed numerical terrain model for the simulation of a backwater flood in Jijia River in Romania.

\subsection{Preparation and entering data for modelling}

The main purpose of using HEC-RAS is calculating the height of the water level, and this is the place where hydrology and hydraulics come together. From 
hydrology, for example, the flow of 100-year water $\left(\mathrm{Q}_{100}\right)$ is known, and this information can be used when working as one of the hydraulic conditions for the given area. Because we are able to deduce the elevation under various flow conditions, the information is useful for assessing inundation, or the flooding of a bridge, or the submerging of culverts and including them in design works. The reason for selection of this particular software was that it is freely accessible on the Internet. The foundations for creating a hydrodynamic model can be topographical maps, orthophoto sensors and a digital model of relief (DMR).

For creation of a hydrodynamic model we used the geometric measurement of the village Kružlov, where the values of the height in the characteristic transverse profiles are entered into a table of geometric data. It is necessary to note that this method of entering values is relatively time consuming, and the values of hydrodynamic model are usually prepared in a GIS environment, namely with the use of the model superstructure HEC-GeoRAS, which functions as an extension for ESRI ArcView (Mišík et al., 2011). The user proceeds according to the pull-down menu, which is found after installation of the extension. The line of the flow, or a network of flows, is created and the lines of the banks and the transverse profile is indicated. These are essential for further work with the model, because in the opposite case it would not be possible to import the exported data into HEC-RAS (Vojtek, 2015). It is more advantageous to determine the individual transverse profiles using GPS coordinates, and reading from the map should be a marginal solution. We put the transverse profiles into the places where the direction of the current changes, namely so that the model has the tendency to linearize the sections between the individual transverse profiles. In HEC-RAS the model is calibrated, and it is possible to condense the transverse profiles for the specific needs to achieve precise spatial data. An important advantage is the possibility of inserting a polygonal LandUse file with the values of the Manning's roughness coefficients for the individual types of use of the country into the model prepared in HEC-GeoRAS. After the entering of these parameters into this superstructure, it is possible to export the data to the HEC-RAS model as a linear element with the basic relief read as the DMR in the form of a TIN file.

At the beginning, we select a path of the water flow. We use the map for better orientation in the environment, or we depict the water flow schematically with a direct line because individual transverse profiles are defined in a coordinate system. Important is entering the beginning and the end of the territory of interest; when the software places these particular points at both ends of the flow line and the endpoint transverse profiles are defined. For entering additional transverse profiles along the length of the flow we used data exported from the HEC-GeoRAS software, where the individual transverse profiles are already defined in the original software environment.

\section{RESULTS AND DISCUSSIONS}

We entered the flood waves to the created model. The HEC-RAS model enables to work with a stable as well as an unstable current, but in our case we did not have values 
for an unstable current available, and so we used the values of culminated flows for return period $\mathrm{N}$-year waters. Figure 2 presents the resulted model of the studied area. With 1D mathematical modelling the values of the N-year flows are used as the boundary conditions needed for starting the calculation. The model evaluation consists of analysis, calibration and verification (Zeleňáková et al., 2019).

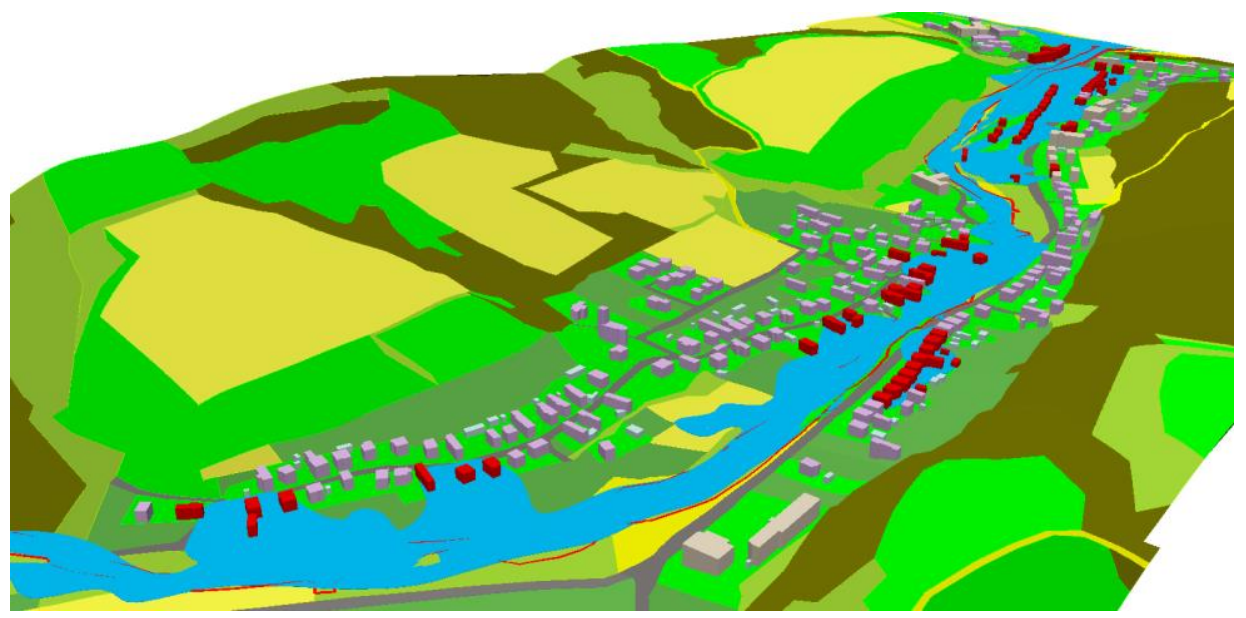

Fig. 2. Flooded area by $Q_{100}$

Verification of the model was done for the flood from 23rd July 2008 which was the most devastated in the area. The discharge during this flood was $70 \mathrm{~m}^{3} \mathrm{~s}^{-1}$; it corresponds to 10 years discharge with return period of 10 years. The longitude profile of the stream is depicted in Fig. 3.

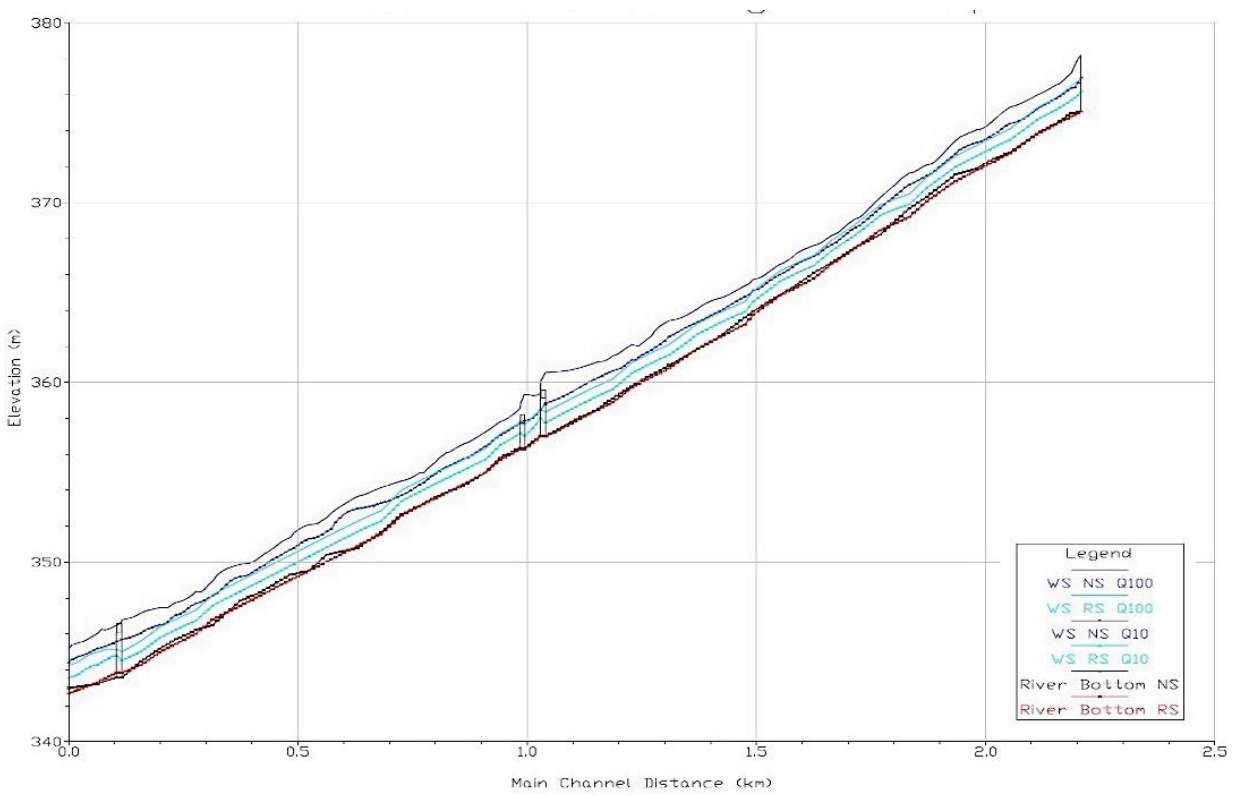

Fig. 3. Longitudal profile of Slatvinec stream 
The course of water level is presented for natural stream (NS) for $\mathrm{Q}_{100}=105 \mathrm{~m}^{3} \mathrm{~s}^{-1}$ (simulated) and $\mathrm{Q}_{10}$ (observed during the flood in 2008) and for simulated $\mathrm{Q}_{100}$ and $\mathrm{Q}_{10}$ for regulated water stream (RS). It is obvious that the discharge of $\mathrm{Q}_{10}$ in natural stream gives almost the same results as $\mathrm{Q}_{100}$ for regulated stream. It presents the high efficiency of the done flood mitigation measures in the area.

Figure 2 presents a 3D model of the resulting inundated area based on the 100year return period discharge $\mathrm{Q} 100=105 \mathrm{~m} . \mathrm{s}-1$, assuming no presence of structural flood protection measures in the studied area.

For the flood from 23rd July 2008 was done also cost analysis. Calculation of flood damage for discharge $\mathrm{Q}_{10}=70 \mathrm{~m}^{3} \mathrm{~s}^{-1}$ during the flood in 2008 is presented in Table 1.

Table 1. Calculation of flood damage for flow $Q_{10}=70 \mathrm{~m}^{3} \mathrm{~s}^{-1}$ during the flood on 23rd July 2008

\begin{tabular}{|l|c|c|c|c|}
\hline Objects & Number of objects & $\begin{array}{c}\text { Flooded area } \\
{\left[\mathbf{m}^{\mathbf{2}}\right]}\end{array}$ & $\begin{array}{c}\text { Unit price } \\
{\left[\mathbf{\epsilon} / \mathbf{m}^{\mathbf{2}}\right]}\end{array}$ & $\begin{array}{c}\text { Damage } \\
{[\boldsymbol{\epsilon}]}\end{array}$ \\
\hline Roads & & 2,156 & 100 & 215,600 \\
\hline Residential buildings & 10 & 1,123 & 174 & 195,402 \\
\hline $\begin{array}{l}\text { Administrative } \\
\text { buildings }\end{array}$ & 1 & 55 & 176 & 9,680 \\
\hline Sport areas & & 56,670 & 0.04 & 2,391 \\
\hline Green areas & 1 & 8,901 & 0.13 & 1,157 \\
\hline Bridges & 1 & 95 & 1697 & 161,215 \\
\hline Small bridges & - & 34 & 1179 & 40,086 \\
\hline Total & - & - & - & $625,531.00$ \\
\hline
\end{tabular}

The value of flood damages calculated from hydrodynamic model of Slatvinec water stream during the flood on 23rd July 2008 was calculated for $625,531 €$. The value of flood damages from flood report in the municipality for the given flood is $587,191 €$. The values highly correspond; the difference of real value of flood damages from modeled one is $6.1 \%$.

\section{DISCUSSION AND CONCLUSIONS}

When working with a hydrodynamic model, knowledge of hydraulics and hydrology is necessary, which with simulations of floods predicts a suitably selected method for modelling various details. These have an impact on the prediction of the flood wave, when conclusions are reflected mainly in the quality of the results, numerical stability and financial effectiveness of modelling works. Quality documents are also a condition for correct results. The ideal case for evaluating results would be if the information acquired from measurements in the field were to be evaluated using a mathematical model. The effectiveness of using a mathematical model is shown to be acceptable from the viewpoint of inputs for a 2D model.

Suitability of HEC-RAS for flood forecasting was proved also by study of Hicks and Peacock (2013). Uncertainty of HEC-RAS model was studied by Jung and Merwade (2012). The possible application of the HEC-RAS model and GIS techniques in river network floodplain delineation was done by Yang et al. (2006). 
Many other studies use effectively HEC-RAS for flood modeling although our study proves the results from modeling in real conditions of flood protection of endangered inundation area (Zeleňáková et al., 2019).

\section{ACKNOWLEDGEMENTS}

This work has been supported by the Slovak Research and Development Agency by supporting the project SK-PT-18-0008 and project SL-PL-18-0033.

\section{REFERENCES}

1. Bakimchandra, O. (2006), Reconstruction of 2003 Daya River Flood, using Multiresolution and Multi-temporal Satellite Imagery. Thesis [online], URL: https://www.iirs.gov.in/iirs/sites/default/files/StudentThesis/bakim thesis2005.pdf

2. Domeneghetti A., Vorogushyn S., Castellarin A., Merz B., Brath A. (2013), Probabilistic flood hazard mapping: effects of uncertain boundary conditions. Hydrology and Earth System Sciences, 17, 3127-3140.

3. Dimitriadis, P., Tegos, A., Oikonomou, A., Pagana, V., Koukouvinos, A., Mamassis, N., Koutsoyiannis, D., Efstratiadis, A. (2016), Comparative evaluation of 1D and quasi-2D hydraulic models based on benchmark and real-world applications for uncertainty assessment in flood mapping. Journal of Hydrology, 534, 478-492.

4. Fijko R., Zeleňáková M. (2015), Riešenie prúdenia vody v otvorenom koryte Stulianského potoka, Lopúchov. Workshop o vode. 1, 1-10. (in Slovak)

5. Fijko, R., Zeleňáková, M., Alkhalaf, I., (2016), Flood risk modelling of stuliansky stream in Lopúchov village, Slovakia. International Journal of Safety and Security Engineering. 6, (3), 529-537.

6. Frazier P.S., Page K.J. (2000), Water body detection and delineation with Landsat TM data. Photogrammetric Engineering and Remote Sensing, 66(12), 1461-1467.

7. Hicks F.E., Peacock T. (2013), Suitability of HEC-RAS for Flood Forecasting. Canadian Water Resources Journal, 30(2), 159-174.

8. Ivanova, O., Ivanov, M., (2016), 1-D Mathematical modelling of flood wave propagation. Chemical Engineering Transactions. 53, 139-144.

9. Jonkman S.N. (2005), Global perspectives on loss of human life caused by floods. Natural hazards, 34(2), 151-175.

10. Jung Y., Merwade V. (2012), Uncertainty Quantification in Flood Inundation Mapping Using Generalized Likelihood Uncertainty Estimate and Sensitivity Analysis. Journal of Hydrologic Engineering, 17(4), 507-520.

11. Komi K., Neal J., Trigg, M.A., Diekkrüger, B. (2017), Modelling of flood hazards extent in data spares areas: a case study of the Oti River Basin, West Africa. Journal of Hydrology: Regional Studies, 10, 122-132.

12. Kron W. (2005), Flood Risk = Hazard • Values • Vulnerability. Water International, 30(1), 58-68.

13. Mišík M., Kučera M., Ando M. (2011), Flood modelling and mapping of urban areas Bratislava: VÚVH. (in Slovak) 
14. Nicholas A.P., Mitchell C.A. (2003), Numerical simulation of overbank processes in topographically complex floodplain environments. Hydrological Processes, 17(4), 727-746.

15. Poretti I., De Amicis M. (2011), An approach for flood hazard modelling and mapping in the medium Valtellina. Natural hazards and earth system sciences, 11(4), 11411151 .

16. Romanescu, G., Stoleriu, C., (2014), An inter-basin backwater overflow (the Buhai Brook and the Ezer reservoir on the Jijia River, Romania). Hydrol. Process., 28, 3118-3131. d

17. Rojas R., Feyen L., Bianchi A., Dosio A. (2012), Assessment of future flood hazard in Europe using a large ensemble of bias-corrected regional climate simulations. Journal of Geophysical Research, 117, D17109.

18. Rozalis S., Morin E., Yair Y., Price C. (2010), Flash flood prediction using an uncalibrated hydrological model and radar rainfall data in a Mediterranean watershed under changing hydrological conditions. Journal of Hydrology, 394(1-2), 245-255.

19. U.S. Army Corps of Engineers. (2016), HEC-RAS River Analysis System, Hydraulic Reference Manual, Version 5.0. USACE, Institute of Water Resources, Hydrologic Engineering Centre, 609 Second Street, Davis, CA 95616.

20. Tehrany M. S., Pradhan, B., Jebur M. N. (2013), Spatial prediction of flood susceptible areas using rule based decision tree (DT) and a novel ensemble bivariate and multivariate statistical models in GIS. Journal of Hydrology, 504, 69-79.

21. Vojtek M. (2015), Flood hazard and flood risk assessment at the local spatial scale: a case study. Geomatics, Natural Hazards and Risk, 7(6), 1973-1992.

22. Yang J., Townsend R.D., Daneshfar B. (2006), Applying the HEC-RAS model and GIS techniques in river network floodplain delineation. Canadian Journal of Civil Engineering, 33(1), 19-28.

23. Zeleňáková M., Fijko R., Labant S., Weiss E., Markovič G., Weiss R. (2019), Flood risk modelling of the Slatvinec stream in Kružlov village, Slovakia. Journal of Cleaner Production, 212, 109-118.

24. Zeleňáková M., Zvijáková L. (2017). Risk analysis within environmental impact assessment of proposed construction activity, Environmental Impact Assessment. Review, 62, 76-89. 